Special issue of the 2nd International Conference on Computational and Experimental Science and Engineering (ICCESEN 2015)

\title{
Extraction and Transport of Humic Acid using Supported Liquid-Membrane Containing Trioctyl Phosphine Oxide (TOPO) as the Carrier
}

\author{
N. TaOualit ${ }^{a, *}$, F.-Z. Azzazi ${ }^{a}$, N.E. Benkadi ${ }^{b}$ And D.E. Hadj-BoussaAd ${ }^{b}$ \\ ${ }^{a}$ Blida University, Process Engineering Department, Laboratoire des Applications ènergètiques et l'Hydrogène, \\ Blida, Algeria \\ ${ }^{b}$ Blida University, Chemistry Department, Blida, Algeria
}

\begin{abstract}
Effluents or liquids of percolation from the discharges (leachates) are charged bacteriologically and especially chemically of mineral substances (mineral ions and heavy metals) and organic (volatile fatty acids, humic substances), which can contaminate soil, surface waters and ground waters. The humic substances, called also refractories, are not easily biodegradable and require concentrating them and/or adsorbing them by implementation of expensive processes. Scientists are looking for alternatives to eliminate or recover these substances. The present study investigates the elimination of humic acid from waste water using supported liquid membrane containing trioctyl phosphine oxide (TOPO) in toluene, as extractant. The supported liquid membrane is composed of a flat sheet of cross-linked polydimethylsiloxane (PDMS). In this study we have: (i) optimized the conditions for humic acid species transfer from feed aqueous phase to stripping phase across PDMS/TOPO/toluene supported liquid membrane; (ii) characterized the membrane by using FTIR technique and by determining the flux $J$, permeability $P$ and diffusion coefficient of the complexed species $D$. Speciation of the humic acid species in the membrane organic carrier (extractant) phase has also been carried out using theoretically derived equations to elucidate the stoichiometry and mechanism of transport of humic acid across the PDMS/TOPO/toluene supported liquid membrane. Optimum conditions of transport for humic acid have been found to be: $\mathrm{pH}=3,[\mathrm{NaOH}]=0.4 \mathrm{M}, E_{\text {extraction }}=$ $94.67 \%, E_{\text {diffusion }}=32.5 \%, J=1.34 \times 10^{-4} \mathrm{mg} \mathrm{cm}^{-2} \mathrm{~s}^{-1}, D=1.16 \times 10^{-2} \mathrm{~cm}^{2} \mathrm{~s}^{-1}$ and $P=2.64 \mathrm{~cm} \mathrm{~s}^{-1}$. Kinetic parameters calculated from the experimental data have been determined. Thermodynamic functions of the several species transfer from the feed solution to the stripping one through the supported liquid membrane, such us enthalpy, entropy and Gibbs free energies, were determined. Positive values of $\Delta H$ and negative values of $\Delta G$ indicate respectively the endothermic and the spontaneous nature of the humic acid extraction in aqueous solution.
\end{abstract}

DOI: 10.12693/APhysPolA.130.115

PACS/topics: 81.05.Lg, 88.40.fh

\section{Introduction}

Humic substances HS are complex and heterogeneous mixtures of polydispersed materials resulting from the decomposition and conversion of organic material. They are naturally found scattered in soil, surface waters and especially in the processing of organic products related to human activities such as compost, manure, discharges and leachates.

Studies have been conducted for several decades to characterize and determine the structure of HS using various nondestructive spectroscopic methods (NMR, IR, UV-visible), or destructive methods (elemental analysis, pyrolysis GC-MS, HPSEC). These methods provide qualitative and quantitative information on the molecular structure of the HS. However, the chemical structure of HS remains poorly defined, mainly because of their different formation processes [1-4].

Reported molecular models $[1,5]$, currently recognize that HS are a heterogeneous combination of molecules held together by hydrophobic interactions of van der Waals type, $\pi-\pi$, ion-dipole. They consist of

\footnotetext{
* corresponding author; e-mail: ntaoualit@hotmail.fr
}

oxidized aromatic nuclei (phenols, methoxyphenols, furans, pyrroles and pyridine) bound by aliphatic chains (alkanes, alkenes, acids, esters, etc.) having acid groups and alcohols [5]. Various analyzes show that whatever their origin (soil, water, or leachate), HS (HA and FA) are composed mainly of carbon, hydrogen, oxygen, nitrogen and functional groups $(\mathrm{COOH}, \mathrm{OH}, \mathrm{C}=\mathrm{O})$. The percentage and the concentration of these elements vary according to the type and origin of HS.

The three main constitutive fractions of HS have different molecular weight according to their polarity and solubility in water: humin is insoluble, humic acid (HA or high molecular weight fraction) is soluble at alkaline $\mathrm{pH}$ and insoluble at acidic $\mathrm{pH}(<2)$, while fulvic acids (FA or fraction of low molecular weight) are soluble in water regardless of the $\mathrm{pH}[6]$.

The isolation and the structure of the HS are subject of many studies $[7,8]$.

These compounds are responsible for the coloration of natural waters and at the time of chlorination, they are likely to generate trihalomethanes (THM), which are potentially carcinogenic, and chlorinated phenols responsible for tastes and odours.

It is necessary in our days to reduce or eliminate these substances. 
Isolation of HS, HA and FA in water is effected by variation of $\mathrm{pH}$ of the medium and by passing through different types of resins [9-12]. Other studies have used solvents to extract the humic substances [13]. Among these methods, that of Thurman and Malcolm [10] is recommended by the International Humic Substances Society.

Mazet et al. [14] have eliminated humic substances in water using grafted celluloses, which constitute an ion exchange material.

In the present study, for the reduction of HA from aqueous solutions we have used the technique of supported liquid-membrane (SLM) which contains an organophosphorous solvating extractant (carrier): the trioctyl phosphine oxide TOPO (Fig. 1).
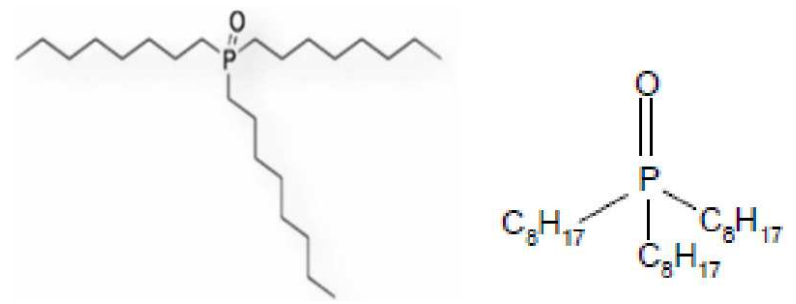

Fig. 1. Structure of the organophosphorous carrier TOPO

SLM technology has recently received considerable attention as an alternative to conventional solvent extraction [15].

The SLM has been reported for the first time by Scholander [16], who studied the transport of oxygen using an aqueous solution of hemoglobin, supported in thin films of cellulose acetate.

The concept of emulsion liquid membrane (ELM) was used for liquid membranes during 1960s and 1970s. However, the simplicity and the possibility of continuous flow through the SLM system have attracted the attention of many scientists around the world in the 1980s.

Since then, SLM have become widely used for the recovery and transport of organic compounds, and metal ions.

SLM was used in the field of biotechnology, hydrometallurgy, capture of greenhouse gases, waste water treatment, separation of unwanted gas and components of natural gas, pharmaceutical industry, environmental and analytical chemistry.

This technique has a high mass transfer rate and inter-species rate and has no problems of emulsification or demulsification encountered in the liquid-membraneextraction (LME) systems.

The SLM technique combines solvent extraction and stripping process in a single step, which provides the maximum driving force for the separation of a target species. The advantages of this extraction technique are the ease of use, relatively high flows and low capital and operating costs [17-19].

Whether it supports the liquid membranes on hollow fiber (HF-SLM) or supports the liquid membrane in a flat sheet (FS SLM), the ligand is incorporated into the walls of the microporous polymeric support. The FSSLM consists of two cells, called feeding and reception compartments. The carrier and the diluent are contained in the polymeric film which is held stationary between both the source and the receiving phases [19-21].

In the present study, a dense (no microporous) flat sheet of cross-linked polydimethylsiloxane (PDMS) was employed as polymeric support containing TOPO as carrier in order to extract HA species and optimize their transfer conditions from feed to stripping aqueous phases across PDMS/TOPO/toluene SLM.

\section{Experimental}

\subsection{Chemicals and materials}

A humic acid solution of $1 \mathrm{~g} / \mathrm{l}$ was prepared according to the method described in the literature [22], based on dissolving of $1 \mathrm{~g}$ of humic acid in a volume of $62.5 \mathrm{ml}$ of $\mathrm{NaOH} 2 \mathrm{~N}$, and combining with distilled water to obtain a volume of $1 \mathrm{l}$. Then the vial thoroughly covered with aluminum foil was placed in the stirring machine for 24 hours. From this stock solution, we prepared by dilution, the solutions at different concentrations. TOPO was purchased from Fluka (97\%) and toluene from Panreac $(99.5 \%)$. A thin flat sheet of RTV-2 silicone PDMS cross-linked ( $2 \%$ cross linked), supplied by Rhodia (ex Rhone-Poulenc, France) was used as the polymeric support. This polymer was prepared, with the collaboration with colleagues from the laboratory of Chemical Molecular and Macromolecular Physics (University of Blida) [23]. The membrane was obtained by swilling PDMS in carrier solution containing $0.2 \mathrm{M}$ of TOPO in toluene for 24 hours. The membrane was freed from the excess of solvent found on its surface by shaking it before being placed in the cell.

\subsection{Experimental device for $H A$ transport}

Transport cell for HA species is composed of two Teflon compartments of $50 \mathrm{ml}$, respectively the source phase of $10 \mathrm{mg} / \mathrm{l} \mathrm{HA}$ solution and receiving phase, containing a solution of $\mathrm{NaOH} 0.4 \mathrm{M}$. The two compartments are separated by the membrane phase of PDMS/TOPO/toluene $0.2 \mathrm{M}$ (SLM), as shown in Fig. 2. Both the source and the receiving aqueous phases were stirred at $600 \mathrm{rpm}$ using electric motors fitted with Pyrex agitators. The active surface of the membrane was $S=8.04 \mathrm{~cm}^{2}$ and the thickness was $e=250-300 \mu \mathrm{m}$. Removing of $1 \mathrm{ml}$ was carried out at time intervals well defined in each compartment. The obtained aqueous phases were proportioned and analyzed at $254 \mathrm{~nm}$ using a Shimadzu UV-1700 pharma spectrophotometer, controlled by a computer. The transport properties were not affected by these samples, the volumes of which are much smaller compared with the initial quite large volumes of aqueous phases. Such samples had not changed them significantly, to require additions of solutions for compensation of losses.

The mass flux can be calculated using Eq. (1), where $J$ is the flux of the transported HA, $V_{\mathrm{R}}$ is the volume of 


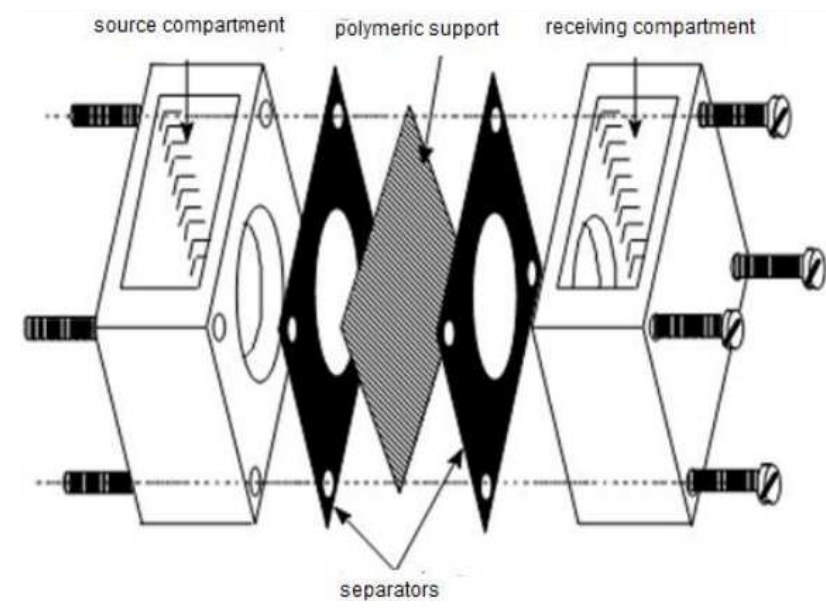

Fig. 2. Experimental transport cell.

receiving phase, $\Delta C$ is the variation of the concentration of the species diffused or complex in the receiving phase, corresponding to time interval $\Delta t[15,24,25]$.

$$
J=\frac{V_{\mathrm{R}}}{\Delta t S} \Delta C
$$

Permeation coefficients $P$ were calculated by:

$$
\ln \frac{C_{\text {ini }}}{C_{\mathrm{t}}}=P \frac{S t}{V_{\mathrm{A}}} .
$$

The flux can be calculated according to:

$$
J=P C_{\text {ini }} \text {. }
$$

The permeability is therefore determined by the slope of the curve:

$$
\ln \frac{C_{\mathrm{ini}}}{C_{\mathrm{t}}}=f(t) .
$$

Here $C_{\mathrm{t}}$ and $C_{\mathrm{ini}}$ are the respective concentrations of HA in the feed phase at given time and at the beginning of reaction, $V_{\mathrm{A}}$ is the volume of the feed solution and $t$ is the process time. The extraction percentage of HA is calculated using the balance of the masses.

\section{Results and discussion}

During all our experiments, we have remarked that HA had diffused from compartment (I) towards compartment (II) in only 2 minutes. The balance is then reached. For the calculation of permeability coefficient, we have taken account of the variation of the concentration of these species before the equilibrium, because beyond $2 \mathrm{~min}$, the relationship (4) becomes not verified.

\subsection{Influence of stirring speed of HA diffusion}

Obtained results show that the permeability coefficient increases with the stirring speed of 400-800 rpm and then decreases (Figs. 3 and 4). This indicates that the thickness of the aqueous boundary layer decreases continuously with the increase of stirring speed to a minimum value reached at the stirring speed of approximately $800 \mathrm{rpm}$, corresponding to the maximum permeability. Higher stirring speeds (> $800 \mathrm{rpm}$ ), leading to some decline in the transport of HA, can be explained by the strong turbulence caused by the agitation, which may cause the movement of certain molecules of TOPO (the carrier) from the membrane $[26,27,15]$. Consequently a stirring rate of $800 \mathrm{rpm}$ was maintained as optimum rate.

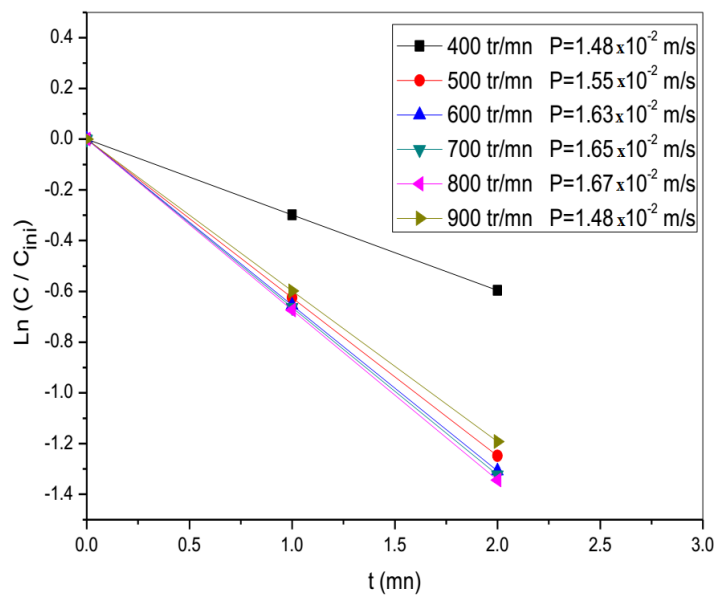

Fig. 3. Variation of $\frac{C_{\mathrm{t}}}{C_{\mathrm{ini}}}=f(t)$.

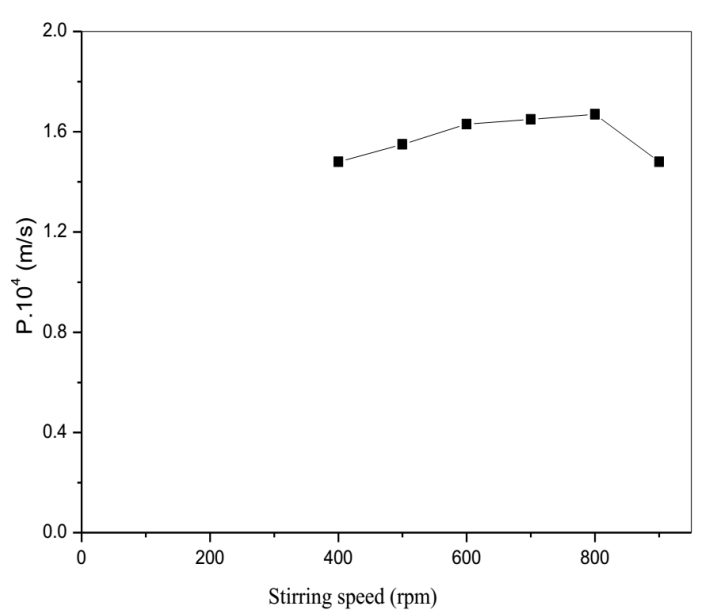

Fig. 4. Effect of stirring speed on HA transport across $\mathrm{PDMS} / \mathrm{TOPO} /$ toluene, $[\mathrm{HA}]=10 \mathrm{mg} / \mathrm{l}$, $[. \mathrm{TOPO}]=0.2 \mathrm{M},[. \mathrm{NaOH}]=0.4 \mathrm{M}$.

\subsection{Influence of TOPO concentration in the membrane phase}

Knowing that the carrier plays an important role in the transport of HA species through the SLM, we have envisaged to follow the evolution of HA concentration in the three phases (aqueous and organic) depending on the TOPO concentration. The selected TOPO concentration range was $0.1 \mathrm{M}, 0.2 \mathrm{M}, 0.5 \mathrm{M}$ and $1 \mathrm{M}$ respectively in toluene as diluent, while other operating conditions were kept constant (temperature, pH, stirring speed, etc.).

Obtained graphical results show that HA concentration decreases in feed phase and increases in the receiving one. This observation allows to confirm the properties of 
HA transport by TOPO. We have also observed that the two curves of each case (Fig. 5a-d) do not tend to zero after a time of 60 minutes of transport and a stationary state is reached after 2 minutes only.
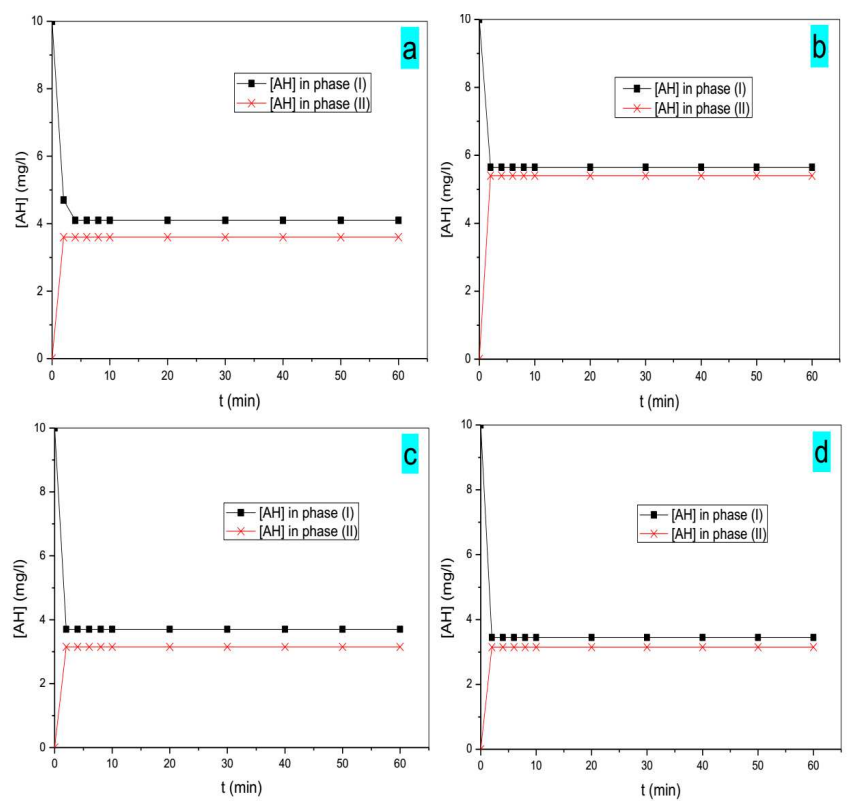

Fig. 5. HA concentration profiles in both compartments, $[\mathrm{HA}]=10 \mathrm{mg} / \mathrm{l},[\mathrm{NaOH}]=0.4 \mathrm{M}$ (a) $[\mathrm{TOPO}]=0.1 \mathrm{M}, \quad$ (b) $[\mathrm{TOPO}]=0.2 \mathrm{M}$, (c) $[\mathrm{TOPO}]=0.5 \mathrm{M},(\mathrm{d})[\mathrm{TOPO}]=1 \mathrm{M}$.

The gap between these two curves represents the accumulated amount of humic acid in the membrane. The symmetry of the two curves shows that a significant amount of HA complexed by TOPO, [AH.TOPO], remains accumulated in the membrane. HA permeability coefficient increases rapidly from $8 \times 10^{-3}$ to $27.5 \times 10^{-3} \mathrm{~ms}^{-1}$, where TOPO concentration varies from $0.1 \mathrm{M}$ to $0.2 \mathrm{M}$, respectively (Fig. 6).

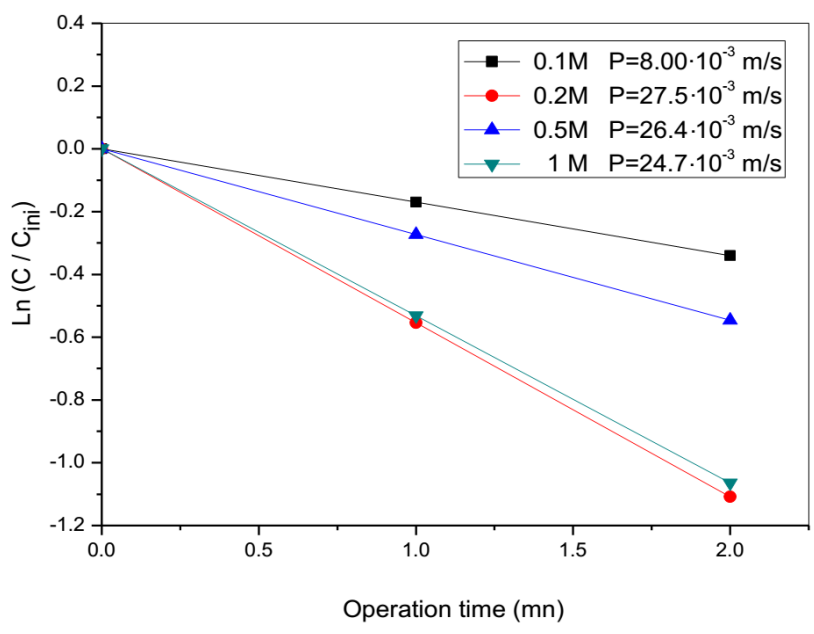

Fig. 6. Effect of TOPO concentration on HA permeation.
The increase in the concentration of TOPO could lead to an important formation of [AH.TOPO] complex and an increase in the concentration gradient inside the membrane. This effect is reflected in the improvement of the extraction percentage $[28,15]$.

Beyond $0.2 \mathrm{M}$ of TOPO, HA permeability coefficient decreases, probably due to the increase of viscosity in the organic solution at higher concentrations of TOPO, which results in an increase in the liquid membrane resistance to the complex species diffusion and a decrease in their migration speed inside the membrane.

This result can be also explained by a possible dimerization of TOPO at high concentrations in the organic phase, which makes the complexation of HA by TOPO at the first interface difficult [29]. Therefore, $0.2 \mathrm{M}$ of TOPO in toluene was maintained for the rest of our study.

\subsection{Effect of $\mathrm{NaOH}$ concentration in strip solution}

To avoid the accumulation of HA in the membrane phase, strip solution must be used to facilitate the decomplexation and release HA to the second interface from the membrane phase.

In order to obtain the appropriate strip solution, two types of commonly used types of solutions were chosen, the sodium hydroxide and water [30]. Obtained results show that $\mathrm{NaOH}$ solution is more effective than water in improving HA transport through the membrane. The extraction and the permeation of $\mathrm{HA}$ are higher when the second compartment receives $\mathrm{NaOH}$ compared to $\mathrm{H}_{2} \mathrm{O}[30,15]$. At equilibrium, extraction yield approaches $100 \%$. Consequently $\mathrm{NaOH}$ solution was selected as the strip solution.

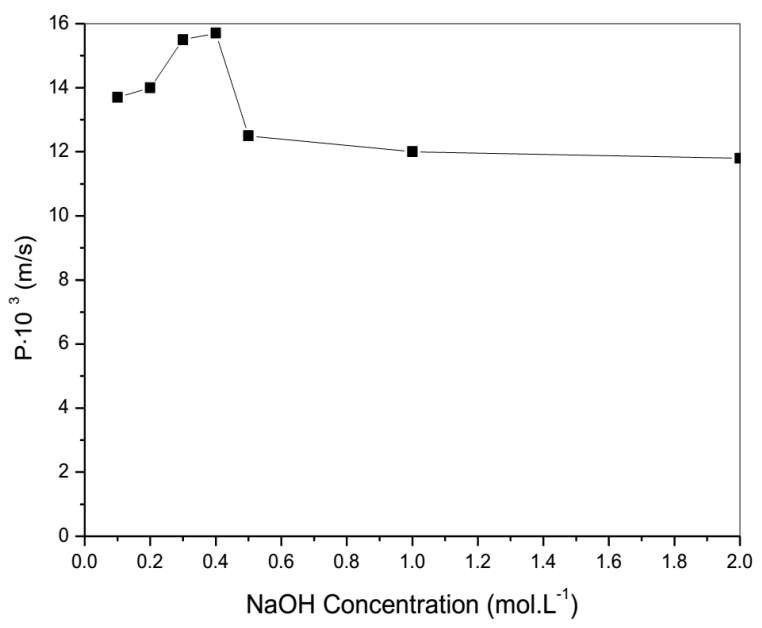

Fig. 7. Effect of $\mathrm{NaOH}$ concentration in the strip phase on HA transport, $[\mathrm{HA}]=10 \mathrm{mg} / 1$, $[\mathrm{TOPO}]=0.2 \mathrm{M}$, $V_{\text {stirring }}=800$ prm.

The experimental results in Fig. 7 show that the increase in the $\mathrm{NaOH}$ concentration from 0.1 to $0.4 \mathrm{M}$ favors the increase of HA permeation coefficients. A maximum permeability coefficient of $15.7 \times 10^{-3} \mathrm{~ms}^{-1}$ is 
observed at a concentration of $\mathrm{NaOH}$ equal to $0.4 \mathrm{M}$. A further increase in $\mathrm{NaOH}$ concentration to $2 \mathrm{M}$, has no significant effect on the HA permeation.

The increase in $\mathrm{HA}$ permeation at $\mathrm{NaOH}$ concentration in range of 0.1 to $0.4 \mathrm{M}$ can be attributed to HA diffusion through SLM due to their decomplexation strengthened (improved) at the second interface.

When $\mathrm{NaOH}$ concentration is greater than $0.4 \mathrm{M}$, the concentration of free HA at the interface and in the extraction solution decreases and approaches zero and the permeation coefficient becomes almost constant. Therefore, $0.4 \mathrm{M}$ of $\mathrm{NaOH}$ was chosen as the optimal concentration of the receiving phase to the rest of our study.

\subsection{Effect of initial HA concentration in the source phase on $H A$ transport}

To investigate the influence of initial HA concentration in the feed compartment, on the transport and recovery of $\mathrm{HA}$ in stripping phase, a range of HA concentrations was selected as follows: $1,2,3,5,8,10$ and $15 \mathrm{mgl}^{-1}$. During this study, the $\mathrm{pH}$ of feed solution was kept at 3 , which was previously found from a preceding study carried out in our laboratory [31].

The second compartment received $\mathrm{NaOH}$ solution of $0.4 \mathrm{M}$ with a stirring speed of $800 \mathrm{rpm}$ in both compartments.

The flow increases significantly from $1.03 \times 10^{-2}$ to $220 \times 10^{-2} \mathrm{mg} \mathrm{s}^{-1} \mathrm{~m}^{-2}$ when the initial concentration of HA increases from 1 to $10 \mathrm{mgl}^{-1}$ in the feed phase, Fig. 7. Thus the flow varies proportionally with the initial concentration of HA. This means that a high initial concentration of $\mathrm{HA}$ in the feed aqueous phase leads to a concentration gradient (molecular) through the membrane, which is more important in the considered interval of concentrations, from 1 to $10 \mathrm{mgl}^{-1}$. At further increase in the initial concentration of HA $(>10 \mathrm{mg} / \mathrm{l})$, the flow stabilizes and a plateau is observed, probably due to the saturation in the SLM and thus, due to a lower effective membrane area and also due to the saturation inside the membrane between the macromolecular mesh (of the crosslinked SLM) by other complexed HA species, which accumulate at the membrane interfacial layer. Same results have been obtained in [32, 33, 15].

\subsection{Effect of temperature}

To study the influence of temperature on the extraction and transport of humic acid through the SLM of $\mathrm{PDMS} / \mathrm{TOPO} /$ toluene, the temperature was varied as follows: 20, 30, 40 and $50^{\circ} \mathrm{C}$. During this study, the operating conditions were maintained at optimum values: $\mathrm{pH}=3,[\mathrm{TOPO}]=0.2 \mathrm{M}, V_{\text {stirring }}=800 \mathrm{prm}$ and $[\mathrm{NaOH}]=0.4 \mathrm{M}$. Table I summarizes the diffusion flux and permeation coefficient values of complexed species. These calculated parameters are practically identical whatever the operating temperature was, with very slight variations. This means that either, the temperature has no influence on the extraction and transport of HA through the chosen SLM or the selected temperature

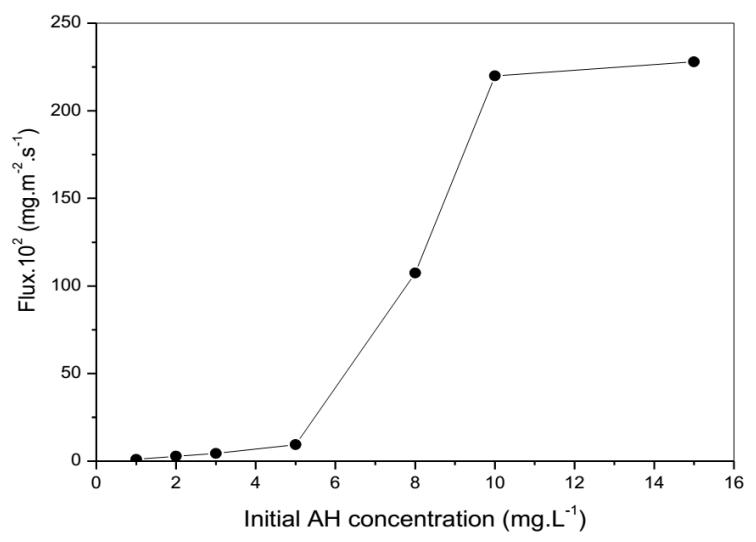

Fig. 8. Effect of initial HA concentration in the source phase on diffusion flux $[\mathrm{NaOH}]=0.4 \mathrm{M},[\mathrm{TOPO}]=0.2 \mathrm{M}$, $V_{\text {stirring }}=800$ prm, $\mathrm{pH}=3$.

range is not adequate and a wider temperature range is recommended.

It should be emphasized that above $50^{\circ} \mathrm{C}$, we have noticed a dilatation of the PDMS/TOPO/toluene SLM. Therefore $30^{\circ} \mathrm{C}$ has been chosen as the optimal temperature in this work.

The diffusion coefficients verify well the first Fick law. The membrane functions as a pump.

TABLE I

HA diffusion flux and permeation as functions of temperature.

\begin{tabular}{c|c|c|c}
\hline \hline Temperature $[\mathrm{K}]$ & 293 & 303 & 313 \\
\hline$E_{\text {extr. }}[\%]$ & 87.94 & 90.3 & 89.33 \\
$E_{\text {diff }}[\%]$ & 51.5 & 49.0 & 52.50 \\
$J\left[\mathrm{mg} \mathrm{cm}^{-2} \mathrm{~s}^{-1}\right]$ & 2.19 & 2.03 & 2.09 \\
$D_{\text {diff }}\left[\mathrm{cm}^{2} \mathrm{~s}^{-1}\right]$ & 12.75 & 12.40 & 12.0 \\
$P\left[\mathrm{~cm} \mathrm{~s}^{-1}\right]$ & 1.57 & 1.67 & 1.70
\end{tabular}

\subsection{Kinetic and thermodynamic modelling of HA permeation through chosen SLM}

Various thermodynamic parameters have been determined using the following thermodynamic equations:

$$
\Delta G=\Delta H-T \Delta S,
$$

where $\Delta G, \Delta H$ and $\Delta S$ are respectively Gibbs free enthalpy, enthalpy and entropy of [AH.TOPO] complex formation reaction crossing the SLM.

After the bringing the aqueous phase (dissociated and undissociated acid solution) and the organic phase (TOPO+toluene) into contact, a certain number of HA molecules are solvated by the extractant TOPO. In this case, there is a coordination structure formed between species.

During the formation of [HA.TOPO] complex, the following aspects can be estimated:

1. The dissociation of the organic acid substance in solution takes place according to the reaction: 
[humic acid $] \longleftrightarrow \mathrm{H}^{+}+$[humic acid $]^{-}$.

2. An associated liaison due to the presence of the pair free of electrons of TOPO (Fig. 1) allows the formation of carried complex by solvatation. Thus, theoretically one molecule of TOPO is associated with one molecule of HA.

$$
\mathrm{HA}_{\mathrm{aq}} \div e \overline{\mathrm{TOPO}} \longleftrightarrow \overline{\mathrm{HA} . \mathrm{TOPO}_{e}}
$$

The constant of this equilibrium is given by the relation:

$$
K_{\text {extr. }}=\frac{\overline{\left[\mathrm{HA}_{\mathrm{TOPO}}\right]}}{\left[\mathrm{HA}_{\mathrm{aq}}\right][\overline{\mathrm{TOPO}}]^{e}} .
$$

The distribution coefficient, in its logarithmic form, is written as:

$$
\log D=\log K_{\text {extr. }}+e \log \text { [TOPO]. }
$$

The equation $\log D$ allows to trace the curve $\log D=$ $f(\log [\mathrm{TOPO}])$, and thus to obtain the coefficient $e$, the slope of the line.

According to Fig. 9 which represents $\log D=$ $f(\log [\mathrm{TOPO}])$, the slope is in the vicinity of 1 , thus the complex formed is of type [HA.TOPO].

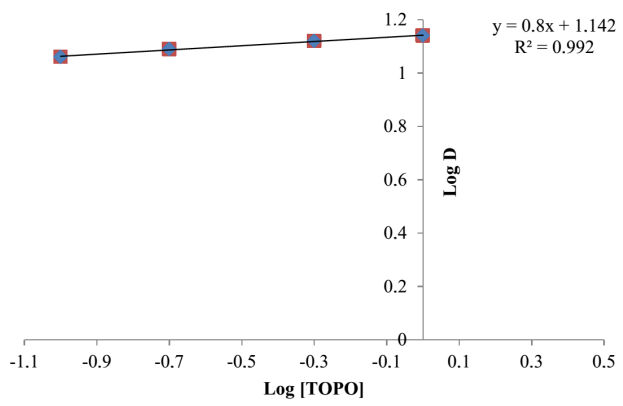

Fig. 9. Variation of $\log D$ as a function of $\log [\mathrm{TOPO}]$.

Equation (8) can be modified as:

$$
K_{\text {extr. }}=\frac{\overline{[\mathrm{HA} \cdot \mathrm{TOPO}]}}{\left[\mathrm{HA}_{\mathrm{aq}}\right][\overline{\mathrm{TOPO}}]} .
$$

Knowing that

$$
\Delta G=-R T \ln K_{\text {extr. }},
$$

values of $K_{\text {extr. }}$ have been determined by combining Eqs. (5) and (10). Thus values of $\Delta H$ and $\Delta S$ were obtained from the slope and the value at the origin of the $\ln K_{\text {extr. }}=f\left(\frac{1}{T}\right)$.

Positive values of $\Delta H$ reflect the endothermic nature of the HA complexation and the values of Gibbs free enthalpy indicate the spontaneous nature of the HA extraction in aqueous solution (Table II).

\section{TABLE II}

Thermodynamic parameters of HA extraction using PDMS/TOPO/toluene SLM.

\begin{tabular}{c|c|c|c}
\hline \hline Temperature $[\mathrm{K}]$ & 293 & 303 & 313 \\
\hline$\Delta H\left[\mathrm{~kJ} \mathrm{~mol}^{-1}\right]$ & 5.3509 & 5.3509 & 5.3509 \\
$\Delta S\left[\mathrm{~J} \mathrm{~mol}^{-1} \mathrm{~K}^{-1}\right]$ & 48.16 & 48.16 & 48.16 \\
$\Delta G\left[\mathrm{~kJ} \mathrm{~mol}^{-1}\right]$ & -8.7609 & -14.5934 & 15.07502
\end{tabular}

3.7. Characterisation of PDMS/TOPO/toluene SLM

The membranes PDMS/TOPO/toluene modified (charged) with [HA.TOPO] complex species, were characterised using chemical techniques as well as Fourier transform infra-red (FTIR) spectroscopy. Figure 10 illustrates the obtained IR spectrum registered between 400 and $4000 \mathrm{~cm}^{-1}$. Results show clearly the appearance of characteristic vibration bands of humic acids. This result confirms the presence and the concentration of HA and carrier inside the membrane matrix.

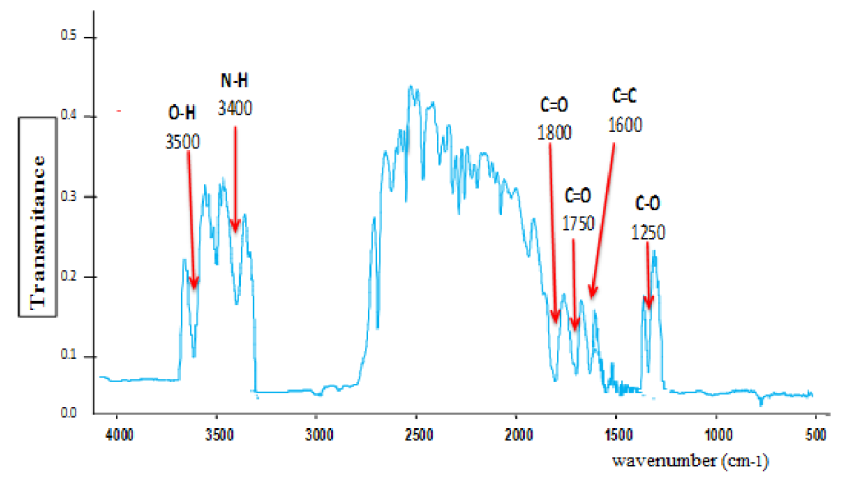

Fig. 10. IR spectrum of PDMS/TOPO/toluene SLM charged with HA species.

\section{Conclusions}

HA transport from an aqueous feed solution through PDMS flat-sheet-supported liquid membrane containing trioctyl phosphine oxide (TOPO) in toluene as a carrier, to $\mathrm{NaOH}$ solution was investigated. Several factors affecting HA transport, such as stirring speed in both compartments, initial HA concentration, feed phase $\mathrm{pH}$ and stripping phase concentration were investigated. Permeation experiments indicate that more than $94 \%$ of HA can be effectively transferred with a permeability coefficient of $27.5 \times 10^{-3} \mathrm{~m} \mathrm{~s}^{-1}$ during 2 min of transport time, with a stirring speed of $800 \mathrm{rpm}$ in both aqueous solutions, an initial HA concentration equal to $10 \mathrm{mg} \mathrm{l}^{-1}$, using $0.2 \mathrm{M}$ of TOPO in toluene, $0.4 \mathrm{~mol} / \mathrm{l}$ of $\mathrm{NaOH}$ as the reception phase, and at $\mathrm{pH}=3$ in the feed solution. Determination of flux, permeability and diffusion coefficient of the complexed species permitted to characterize the SLM. Obtained results establish that the technique using supported liquid-membrane PDMS/TOPO/toluene is suitable for treating and concentrating effluents containing several organic substances susceptible to be toxic. It leads us to test this type of membranes in other areas and especially those related to metal ions, such as those of effluents from surface treatment workshops in order to protect the environment and recover the metal.

\section{References}

[1] B. Eyheraguibel, Ph.D. Thesis, National Polytechnic Institute of Toulouse, France 2004.

[2] L.P. Canellas, D.B. Zandonadi, J.G. Busato, M.A. Baldotto, M.L. Simoes, L. Martin-Neto, A.R. Faqonho, R. Spaccini, A. Piccolo, Soil Sci. 173, 624 (2008). 
[3] T.L. Chung, J.S. Chen, C.Y. Chiu, G. Tian, J. For. Res. 17, 1 (2011).

[4] S. Nasir, B. Sarfaraz Tahira, T. Vincent Verheyent, A.L. Chaffee, Fuel Process. Technol. 92, 983 (2011).

[5] S. Trevisan, Ph.D. Thesis, University of Padoue, Italy 2010.

[6] A. Tahiri, J. Destin, P. Druart, P. Thonart, BASE 18, 436 (2014).

[7] E.T. Gjessing, L. Berglind, Arch. Hydrobiol. 92, 24 (1981).

[8] R.F. Christman, E.T. Gjessing, Aquatic and Terrestrial Humic Materials, Ann Arbor Science, Ann Arbor 1983.

[9] G.R. Aiken, E.M. Thurman, R.L. Malcolm, H.F. Walton, Anal. Chem. 51, 1799 (1979).

[10] E.M. Thurman, R.L. Malcolm, Environ. Sci. Technol. 15, 463 (1981).

[11] P. LeCloirec, G. Martin, Aqua 4, 215 (1985).

[12] S.A. Daignault, D.K. Noot, D.T. Williams, P.M. Huck, Wat. Res. 22, 803 (1988).

[13] J. Ayele, M. Mazet, Envir. Technol. Lett. 11, 555 (1990).

[14] M. Mazet, J. Ayele, I. Rigaudie, Wat. Res. 26, 409 (1992).

[15] X. Yang, H. Duan, D. Shi, R. Yang, S. Wang, H. Guo, Chem. Eng. Process. 93, 79 (2015).

[16] S.V. Kislik, Liquid membranes: principles and applications in chemical separations and wastewater treatment, 1st ed., Elsevier, UK 2010.

[17] C. Zidi, R. Tayeb, M. Dhahbi, J. Mater. Environ. Sci. 5, 779 (2014).

[18] N. Taoualit, D.E. Hadj Boussaad, Desalination 144 273 (2002).
[19] N.M. Kocherginsky, Q. Yang, L. Seelam, Sep. Purif. Technol. 53, 171 (2007).

[20] P.R. Danesi, J. Membrane Sci. 20, 231 (1984).

[21] R. Tayeb, S. Tingry, M. Dhahbi, P. Seta, J. Soc. Chim. Tunisie 7, 187 (2005).

[22] F. Zermane, M.W. Naceur, B. Cheknane, N. Ait Messaoudene, Desalination 179, 375 (2005).

[23] H. Benguergoura, T. Aouak, S. Moulay, J. Membrane Sci. 229, 107 (2004).

[24] O. Arous, F. Saad Saoud, M. Amara, H. Kerdjoudj, Mater. Sci. Applications 2, 615 (2011).

[25] N. Taoualit, D.E. Hadj-Boussaad, Desalination 193 , 321 (2006).

[26] A.A. Amiri, A. Safavi, A.R. Hasaninejad, H. Shrghia, M. Shamsipur, J. Membrane Sci. 325, 295 (2008).

[27] J. Narayanan, K. Palanivelu, Indian J. Chem. Techn. 15, 266 (2008).

[28] F.T. Minhas, S. Memon, I. Qureshi, M. Mujahid, M.I. Bhanger, C. R. Chim. 16, 742 (2013).

[29] I. Ait Khaldoun, M.Sc. Thesis, Tizi-Ouzou University, Algeria 2011.

[30] S.J. Li, H.I. Chen, L. Zhang, Sep. Purif. Technol. 66, 25 (2009).

[31] F.Z. Azzazi, M.Sc. Thesis, Blida University, Algeria 2015.

[32] F.Z. El Aamrani, A. Kumar, L. Beyer, J.L. Cortina, A.M. Sastre, Hydrometallurgy 50, 315 (1998).

[33] F.J. Alguacil, M. Alonso, Hydrometallurgy 74, 157 (2004). 